\title{
Scour monitoring of a bridge pier through eigenfrequencies analysis
}

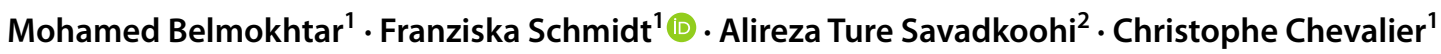

Received: 5 October 2020 / Accepted: 27 January 2021 / Published online: 10 February 2021

(C) The Author(s) 2021 OPEN

\begin{abstract}
This paper presents an innovative method for scour monitoring, based on the analysis of the dynamic response of a bridge pier embedded in the riverbed. Apart from the mechanical and physical characteristics of the pier itself, soilstructure interaction (SSI) has an impact on the dynamical behaviour of the system. This is particularly the case for eigenfrequencies of the pier which decrease when the free length increases. In this paper, analytical developments are carried out for an Euler-Bernoulli beam, modelling the pier which is embedded in the soil with Winkler springs for SSI. By using Hamilton's principle and endowing the specific boundary conditions, the system frequencies are assessed by looking for roots of the characteristic equation of the system. These eigenfrequencies are then compared with those of an equivalent cantilevered beam, which can be expressed analytically. Moreover, experiments are carried out to validate the concept of equivalent length as a parameter of the inverse problem, linking the dynamic behaviour of the system and the embedded length.
\end{abstract}

\begin{tabular}{|c|c|}
\hline \multicolumn{2}{|c|}{ Abbreviations } \\
\hline$E$ & $\begin{array}{l}\text { Young Modulus of the considered beam } \\
\text { (GPa) }\end{array}$ \\
\hline I & $\begin{array}{l}\text { Moment of inertia about } x \text {-axis of the consid- } \\
\text { ered beam }\left(\mathrm{m}^{4}\right)\end{array}$ \\
\hline$\rho$ & $\begin{array}{l}\text { Mass density of the considered beam }\left(\mathrm{kg} \mathrm{m}^{-3}\right. \\
\text { ) }\end{array}$ \\
\hline$A$ & Cross-section of the considered beam $\left(\mathrm{m}^{2}\right)$ \\
\hline$k$ & $\begin{array}{l}\text { Elasticity reaction of the soil modeled by } \\
\text { springs }\left(\mathrm{kN} \mathrm{m}^{-2}\right)\end{array}$ \\
\hline$g$ & Shear modulus between soil springs (kN) \\
\hline$x$ & Position along neutral axis of the beam (m) \\
\hline$t$ & Time (s) \\
\hline$v$ & $\begin{array}{l}\text { Displacement in flexion of the considered } \\
\text { beam }(m)\end{array}$ \\
\hline • & $=\frac{\partial^{2}}{\partial t^{2}}, \mathbf{o}^{\prime}=\frac{\partial}{\partial x^{\prime}}, \bullet^{(j)}=\frac{\partial^{j}}{\partial x^{j}}$ \\
\hline$T, E$ and $U$ & $\begin{array}{l}\text { Kinetic energy, Strain energy and External } \\
\text { force energy }(J)\end{array}$ \\
\hline$q_{r}$ & Temporal function of the $r$ th mode \\
\hline$V_{r}$ & Shape function of the $r$ th mode $(\mathrm{m})$ \\
\hline$\omega_{r}$ & Temporal pulsation of the $r$ th mode $\left(s^{-1}\right)$ \\
\hline
\end{tabular}

\begin{tabular}{|c|c|}
\hline$\lambda_{r}$ & Space pulsation of the $r$ th mode $\left(\mathrm{m}^{-1}\right)$ \\
\hline & Non-dimension associate function \\
\hline$\Omega_{r}$ & $\begin{array}{l}\text { Temporal pulsation of the } r \text { th mode for a free } \\
\text { cantilevered beam }\left(\mathrm{s}^{-1}\right)\end{array}$ \\
\hline$\beta_{r}$ & $\begin{array}{l}\text { Spatial pulsation of the } r \text { th mode for a free } \\
\text { cantilevered beam }\left(\mathrm{m}^{-1}\right)\end{array}$ \\
\hline$-a$ & Active length $(\mathrm{m})$ \\
\hline & Free equivalent added legth (m) \\
\hline
\end{tabular}

\section{Introduction}

Scour is a consequence of the erosive action of flowing water which leads to the removal of material from the riverbed. When there is an obstacle in the river flow, like a bridge, scour causes a digging of the sediments around the piers or the abutments. In a point of view of the health of the structure, this phenomenon may represent an issue: indeed, scour is the primary cause of bridge collapses [21]. A study of over 500 bridges failures in USA has assigned $53 \%$ of American bridge failures to hydraulic risk [32]. Studies have also shown how scour may lead to expensive

Franziska Schmidt, franziska.schmidt@univ-eiffel.fr | ${ }^{1}$ Université Gustave Eiffel, Champs-sur-Marne, France. ${ }^{2}$ Univ Lyon, ENTPE, LTDS UMR CNRS 5513, Rue Maurice Audin, 69518 Vaulx-en-Velin Cedex, France. 
structural maintenance [17] to avoid casualties and repair blocked connections. To avoid these risks and to monitor scour-depth, several methods have been developed the past years [23].

Among the widely used water depth-measuring devices, we can cite magnetic sliding collars [14], float-out systems [2], radar systems [10] and time-domain reflectometry [35]. Two disadvantages of these methods are the difficulty of implementation and the retrieval of information on the soil behaviour, which may be an issue for the structure [36].

An alternative is the detection of scour damage using vibration-based structural health monitoring [26, 27]. Methods were developed to detect changes in dynamic characteristics, such as the natural frequency, the mode shape curvature and the dynamic rigidity $[8,12,16]$. At this stage, water is considered as an added mass [34]. Using auto-regressive moving average vector (ARMAV, $[3,20]$ ) techniques, [11] showed numerically and experimentally that mode shapes and eigenfrequencies of bridges change under scour variation: more precisely, an increase of scour depth implies a decrease of eigenfrequencies. On the structural level, there are two ways to model scour, which are a loss in foundation stiffness around the pier [11] and an evolution of geometric parameters, like the free length [24]. This article implements the second point of view.

Currently, many works study the inverse relation between the frequency response of a bridge pier and scour depth. Discussions focus on combining several technologies, as water depth-measuring devices and analysis of dynamic behavior of a structural element $[4,5,37]$.

[24] proposed direct scour monitoring, using the frequency response of a pier. For that, an experimental full scale pile embedded in a block of sand was investigated. For each value of the scour depth an impact was applied in order to study the dynamic response of the pier. Then, the intrinsic soil parameters have been determined using a geotechnical method based on the Cone Penetration Test (CPT) [29]. [4] focused their studies on the influence of soil characteristics and geometry of the pier on the natural frequencies of the pier under scour phenomenon.

[37] proposed an indirect scour monitoring method using rods that are embedded in the riverbed and equipped with fiber-optic Bragg sensors. The fundamental frequencies of the rod are identified from the strain response history in the time domain. Numerical modeling is carried out in order to model the SSI with elastic springs, and then to correlate the first frequency with the scour depth.

[5] proposed a new type of low-cost rod-sensor using accelerometers, which were also used for direct monitoring of the response of a pile in [24]. For a given geometry and material of the rod, and type of soil, there is a similarity of eigenfrequency variation with scour depth between the rod that is embedded in soil and a cantilevered beam of a given corresponding length [6]. A new parameter is then defined, named the equivalent free length which is a function of the mechanical and inertial characteristics of the beam and the mechanical characteristic of the soil

The work presented here aims at analytical developments of this equivalent free length. By modelling the interaction between the soil and the structure, analytical expressions are written for both the response of a beam embedded in soil and the response of the equivalent cantilevered beam. The developed models remain general and can be applied for direct monitoring (bridge pier) or indirect monitoring (rod/pile sensor). Nevertheless, considering certain assumptions made in these developments, it is more suitable for indirect scour monitoring.

The paper is structured as follows: First, by considering an Euler-Bernoulli Beam [15] partially embedded in a Pasternak Soil [22] and by using Hamilton's principle, the analytical expression for the first natural frequency is derived and compared to numerical results. Then, an asymptotic approach is carried out to approximate the natural frequencies of the system. In a last Section, using fast Fourier Transform algorithm, this analytical expression of natural frequencies is compared to data from experiments. These experiments are carried out for the free response of a "pile" partially embedded in sand: comments and conclusions are given.

\section{Analytical soil-structure interaction model}

This Section proposes an analytical development for the eigenfrequencies of rod-sensors that allows for the indirect monitoring (see Fig. 1). Rod sensors are beam-like elements, that can be compared to very flexible piers.

Let us consider a linear Euler Bernoulli beam [15] partially embedded in a Pasternak soil [22] with lateral displacement $v(x, t)$ (see Fig. 2), where $E, I, \rho$ and $A$ are respectively the Young modulus, the moment of inertia, the mass density and the cross section of the beam. Pasternak's model depends on two parameters, namely $k$ the elastic reaction modulus of springs and $g$ the shear modulus between the springs. The parameters in the Pasternak model are dependant, and Vlasov [31] defined an iterative method to find the couple $(k, g)$. However, we can notice that when $g=0$, a Pasternak soil model is similar to a Winkler soil model [33].

\subsection{Variational formulation of the problem}

Because of the presence of an interface (between the buried and the non-buried parts in the soil), this problem 
Fig. 1 Scour rod sensor

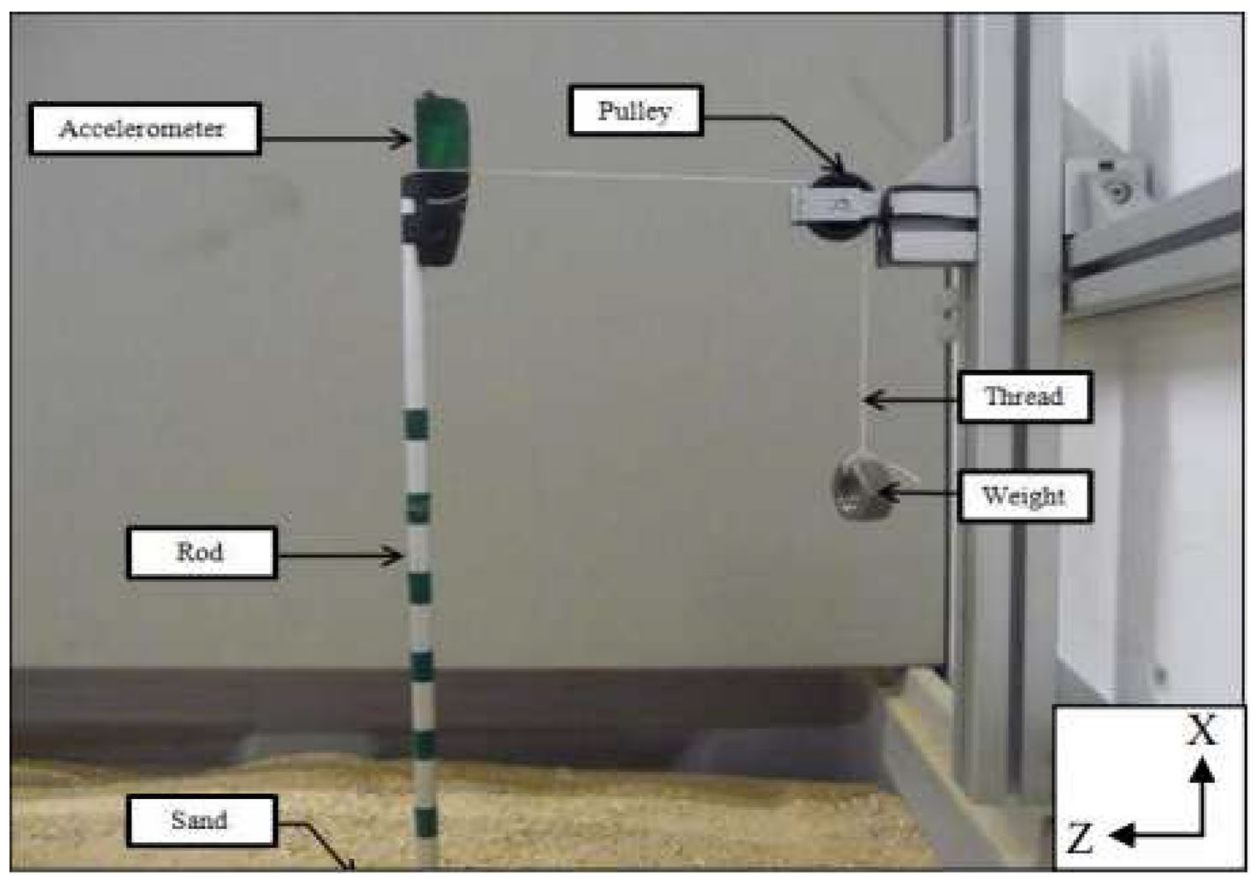

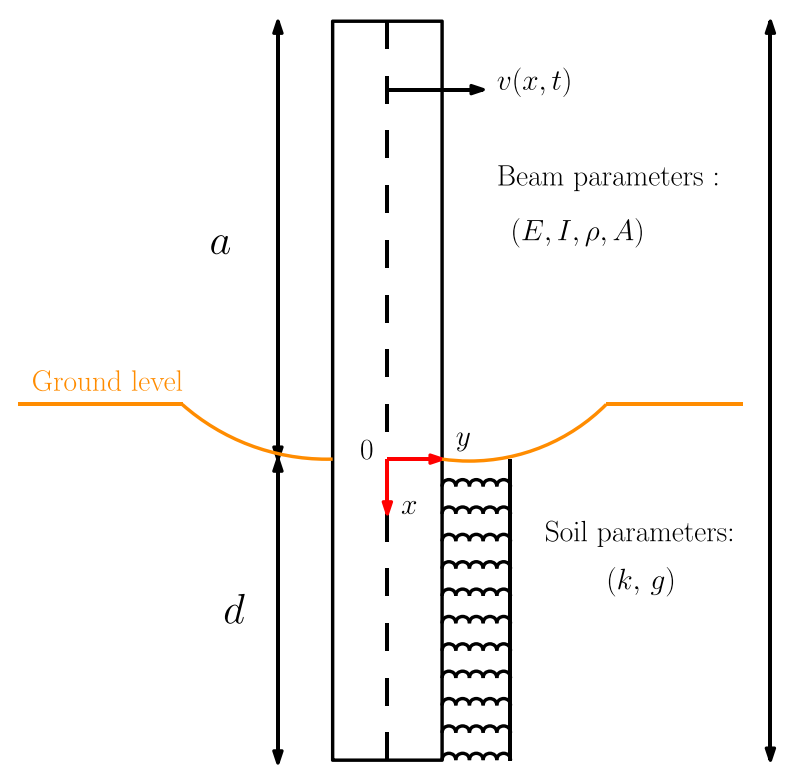

Fig. 2 Schematic of the considered problem, where the ground level is at $x=0$

has specific boundary conditions. Consequently, the variational approach is established using Hamilton's principle between timestamps $t_{1}$ and $t_{2}$ :

$\int_{t_{1}}^{t_{2}}(\delta T-\delta E+\delta U) d t=0$

where $\delta T$ is the variational Kinetic Energy defined by :

$$
\begin{aligned}
\int_{t_{1}}^{t_{2}} \delta T d t & =\rho A \int_{-a}^{d}\left([\dot{v}(x, t) \delta v(x, t)]_{t_{1}}^{t_{2}}\right. \\
& \left.-\int_{t_{1}}^{t_{2}} \ddot{v}(x, t) \delta v(x, t) d t\right) d x .
\end{aligned}
$$

- and $\bullet$ are respectively the first and second partial derivative with respect to the time.

The variation of strain energy $\delta E$ can be written as:

$$
\begin{aligned}
\int_{t_{1}}^{t_{2}} \delta E d t= & \int_{t_{1}}^{t_{2}}\left(\left[\operatorname{ElV}^{\prime \prime}(x, t) \delta v^{\prime}(x, t)\right]_{-a}^{d}\right. \\
& \left.-\left[E / v^{(3)}(x, t) \delta v(x, t)\right]_{-a}^{d}\right) \\
& +\int_{t_{1}}^{t_{2}}\left(\int_{-a}^{d} E l v^{(4)}(x, t) \delta v(x, t) d x\right) d t .
\end{aligned}
$$

$\bullet^{\prime}, \bullet^{\prime \prime}, \bullet^{(3)}$ and $\bullet$ (4) are space derivatives of $v(x, t)$ with respect to $x$.

$\delta U$ is defined as:

$$
\begin{aligned}
\int_{t_{1}}^{t_{2}} \delta U d t= & \int_{t_{1}}^{t_{2}}\left(\int_{-a}^{d}(k v(x, t)\right. \\
& \left.\left.-g v^{\prime \prime}(x, t)\right) H_{0}(x) \delta v(x, t) d x\right) d t,
\end{aligned}
$$

where $H_{0}$ denotes the Heaviside function.

Combining Eqs. (1)-(4) leads to: 


$$
\begin{aligned}
& \int_{t_{1}}^{t_{2}}\left(\int _ { - a } ^ { d } \left\{E V^{(4)}(x, t)+\rho A \ddot{v}(x, t)\right.\right. \\
& \left.\left.+\left(k v(x, t)-g v^{\prime \prime}(x, t)\right) H_{0}(x)\right\} \delta v(x, t) d x\right) d t=0,
\end{aligned}
$$

which should be supplemented by boundary conditions.

Due to the interface between the soil and the free area, the problem is non-linear. But we treat the problem as two separate linear problems. Governing system equations are given by:

$$
\begin{cases}v^{(4)}(x, t)+\frac{\rho A}{E l} \ddot{v}(x, t)=0 & \text {, if } x \in[-a, 0], \\ v^{(4)}(x, t)-\frac{g}{E l} v^{\prime \prime}(x, t)+\frac{k}{E l} v(x, t)+\frac{\rho A}{E l} \ddot{v}(x, t)=0 & , \text { if } x \in[0, d] .\end{cases}
$$

\subsection{Modal analysis}

The spatio-temporal displacement of the system, i.e $v(x, t)$, is written as,

$v(x, t)=\sum_{i=0}^{\infty} q_{i}(t) V_{i}(x)$,

where $q_{i}(t)$ and $V_{i}(x)$ are the modal functions corresponding to the $i$ th mode. We can project Eq. (6) on the $r^{\text {th }}$ mode via using orthogonality properties. It leads to:

$\begin{cases}\left(V_{r}^{(4)}(x)+\beta_{r}^{4} V_{r}(x)\right) q_{r}(t)=0 & \text {, if } x \in[-a, 0], \\ \left.V_{r}^{(4)}(x)-4 \delta_{r}^{2} \mu_{r} V_{r}^{\prime \prime}(x)+4 \delta_{r}^{4} V_{r}(x)\right) q_{r}(t)=0 & , \text { if } x \in[0, d],\end{cases}$

with characteristic elements defined by [28]:

$\left\{\begin{array}{l}\omega_{r}^{2}=-\frac{\ddot{q}_{r}(t)}{q_{r}(t)}, \\ \beta_{r}^{4}=\frac{\rho A \omega_{r}^{2}}{E I}, \\ \delta_{r}^{4}=\frac{\left(k-\rho A \omega_{r}^{2}\right)}{4 E I}=\frac{k}{4 E I}-\frac{\beta_{r}^{4}}{4}, \\ \gamma_{r}^{2}=\frac{\left(k-\rho A \omega_{r}^{2}\right)}{g}, \\ \mu_{r}=\frac{g}{\delta_{r}^{2}}=\frac{g}{2 \sqrt{\left(k-\rho A \omega_{r}^{2}\right) E I}} .\end{array}\right.$

For further developments, we introduce following dimensionless variables:

$\tilde{x}=\frac{x}{L} \quad, \tilde{V}_{r}=\frac{V_{r}}{L} \quad, \tilde{\beta}_{r}^{4}=\beta_{r}^{4} L^{4} \quad, \tilde{\delta}_{r}^{4}=\delta_{r}^{4} L^{4}$.

\subsection{Specific boundary conditions and modal behaviours}

Eigenfrequencies depend on the boundary conditions of the dynamical system. This section aims at writing the nontrivial solutions of the system leading to eigenfrequencies detection. First, at $\tilde{x}=-\frac{a}{L}$ the beam is considered free, so: $\tilde{V}_{r}^{\prime \prime}\left(-\frac{a}{L}\right)=0$,

$\tilde{V}_{r}^{(3)}\left(-\frac{a}{L}\right)=0$.

Then, the non-linear problem (Eq. (5)) is treated as two linear problems on two different spaces with continuous kinematics (continuous beam). In fact, Pasternak's model [22] introduces a continuous load applied by the soil on the solid:

$$
\begin{gathered}
\tilde{V}_{r}\left(0^{-}\right)=\tilde{V}\left(0^{+}\right), \\
\tilde{V}_{r}^{\prime}\left(0^{-}\right)=\tilde{V}_{r}^{\prime}\left(0^{+}\right), \\
\tilde{V}_{r}^{\prime \prime}\left(0^{-}\right)=\tilde{V}_{r}^{\prime \prime}\left(0^{+}\right), \\
\tilde{V}_{r}^{(3)}\left(0^{-}\right)=\tilde{V}_{r}^{(3)}\left(0^{+}\right) .
\end{gathered}
$$

To solve Eq. (8), let us assume:

$\frac{k}{\rho A \omega_{r}^{2}}>>1$

Assumption (13) signifies that for first low frequencies of the system, the rigidity of the soil $(k)$ is much higher than the quantity $\rho A \omega_{r}^{2}$. It is the case for ordinary soil types as sand or clay.

Moreover let us suppose $\tilde{V}_{r}$ is a combination of wave functions of type $\exp \left(\lambda_{r} \tilde{x}\right)$. Consequently, $\lambda_{r}$ is the solution of:

$\begin{array}{ll}\lambda_{r}^{2}= \pm \tilde{\beta}_{r}^{2} & \text {, if } x \in[-a, 0] \\ \lambda_{r}= \pm \tilde{\delta}_{r} \sqrt{2\left(\mu_{r} \pm \sqrt{\mu_{r}-1}\right)}, & \text { if } x \in[0, d] .\end{array}$

Let us detail the solutions of Eq. (14) for each segment:

- Free part, i.e for $\tilde{x} \in\left[-\frac{a}{L}, 0\right]$, Eq. (14) has the following solution:

$$
\begin{aligned}
\tilde{V}_{r}(\tilde{x})= & A_{1} \cos \left(\tilde{\beta_{r}} \tilde{x}\right)+A_{2} \sin \left(\tilde{\beta_{r}} \tilde{x}\right) \\
& +A_{3} \cosh \left(\tilde{\beta_{r}} \tilde{x}\right)+A_{4} \sinh \left(\tilde{\beta_{r}} \tilde{x}\right)
\end{aligned}
$$

with $A_{i} \in \mathbb{R}, \forall i \in \llbracket 1 ; 4 \rrbracket$.

- Embedded part, i.e for $\tilde{x} \in\left[0, \frac{d}{L}\right]$, the solution of Eq. (14) depends on the value of $\mu_{r}$. By distinguishing the numerical values of $\mu_{r}$ (defined in Equation (9)) and 
defining $\phi_{i}$ the solutions of the characteristic equation, we can distinguish 3 cases,

- Case I: $0<\mu_{r}<1$.

$\lambda_{r}= \pm \phi_{1} \pm i \phi_{2}$

with $i^{2}=-1, \phi_{1}=\tilde{\delta}_{r} \sqrt{1+\mu_{r}}$ and $\phi_{2}=\tilde{\delta}_{r} \sqrt{1-\mu_{r}}$.

$\tilde{V}_{r}(x)=\exp \left(\phi_{1} \tilde{x}\right)\left(B_{1} \cos \left(\phi_{2} \tilde{x}\right)+B_{2} \sin \left(\phi_{2} \tilde{x}\right)\right)$ $+\exp \left(-\phi_{1} \tilde{x}\right)\left(B_{3} \cos \left(\phi_{2} \tilde{x}\right)+B_{4} \sin \left(\phi_{2} \tilde{x}\right)\right.$

- Case II: $\mu_{r}=1$.

$\lambda_{r}= \pm \sqrt{2} \tilde{\delta}_{r}= \pm \phi$,

$\tilde{V}_{r}(x)=\exp (\phi \tilde{x})\left(B_{1}+B_{2} \tilde{x}\right)+\exp (-\phi \tilde{x})\left(B_{3}+B_{4} \tilde{x}\right)$

- Case III: $\mu_{r}>1$.

$\lambda_{r}= \pm \phi_{1} \pm \phi_{2}$

with $\phi_{1}=\tilde{\delta}_{r} \sqrt{1+\mu_{r}}$ and $\phi_{2}=\tilde{\delta}_{r} \sqrt{\mu_{r}-1}$,

$\tilde{V}_{r}(x)=\exp \left(\phi_{1} \tilde{x}\right)\left(B_{1} \cosh \left(\phi_{2} \tilde{x}\right)+B_{2} \sinh \left(\phi_{2} \tilde{x}\right)\right)$ $+\exp \left(-\phi_{1} \tilde{x}\right)\left(B_{3} \cosh \left(\phi_{2} \tilde{x}\right)+B_{4} \sinh \left(\phi_{2} \tilde{x}\right)\right)$

For the rest of the study, let suppose small displacements at $\tilde{x}=\frac{d}{L}$, i.e we assume $d$ is big enough, so:

$\left|\tilde{V}_{r}\left(\frac{d}{L}\right)\right|<<1$

Equation (22) leads to neglectthe coefficient in front of positive exponential:
$\left(B_{1}, B_{2}\right)=(0,0)$.

So, with Eqs. (11), (12) and (23), the eigenfrequencies $\omega_{r}$ can be written as solutions of:

$\operatorname{Det}\left(C\left(\omega_{r}, \mu_{r}\right)\right)=0$,

where $C$ is a $6 \times 6$ matrix depending on $\mu_{r}$ and $\omega_{r}$ (see Appendix 1).

In Figs. 3 and 4, the first natural frequency $(r=1)$ is plotted as a function of scour depth. Results are solutions of Eq. (24) detected by Newton's method in Matlab ${ }^{\circledR}$.

In Fig. 3, the influence of the ratio between the rigidity of soil and flexural rigidity of the beam, i.e $\frac{k}{4 E I}$, is studied by supposing $\mu=0$ (i.e $g=0$ ). In this case the higher rigidity of the soil, the faster the decrease in the value of the eigenfrequency is.

It is shown that $g$ is small with respect to $k$ [1]. So that, we make a linearization at the first order of the coefficient $\mu_{r}=\mu=\frac{g}{2 \sqrt{k E l}}$ in order to solve numerically Eq. (24). As a consequence, we assume that $\mu$ is independent of $\omega_{r}$. That is to say that it is the same for all modes. Figure 4 is a result from this assumption and shows how the coefficient $\mu_{1}$ creates a translation of the eigenfrequency without changing the trend of the curve.

The analysis of the function of the first natural frequency $f_{1}\left(\frac{a}{L}\right)$ shows that there exists a relation between the eigenfrequencies and the scour level. For each couple $(k, g)$, we can identify the curve trend as an inverse function in view of the decrease variation. Even more, when $\frac{k}{4 E I}$ is big (over $1000 \mathrm{~m}^{-4}$ ), the curve trend can be assimilated to a cantilevered beam. In general we will suppose that $k$ is bigger than all the other parameters to be sure that hypothesis (13) makes sense. This assumption is generally
Fig. 3 Influence of the ratio $\frac{k}{4 E I}$ on the first natural frequency by supposing $\mu=0$

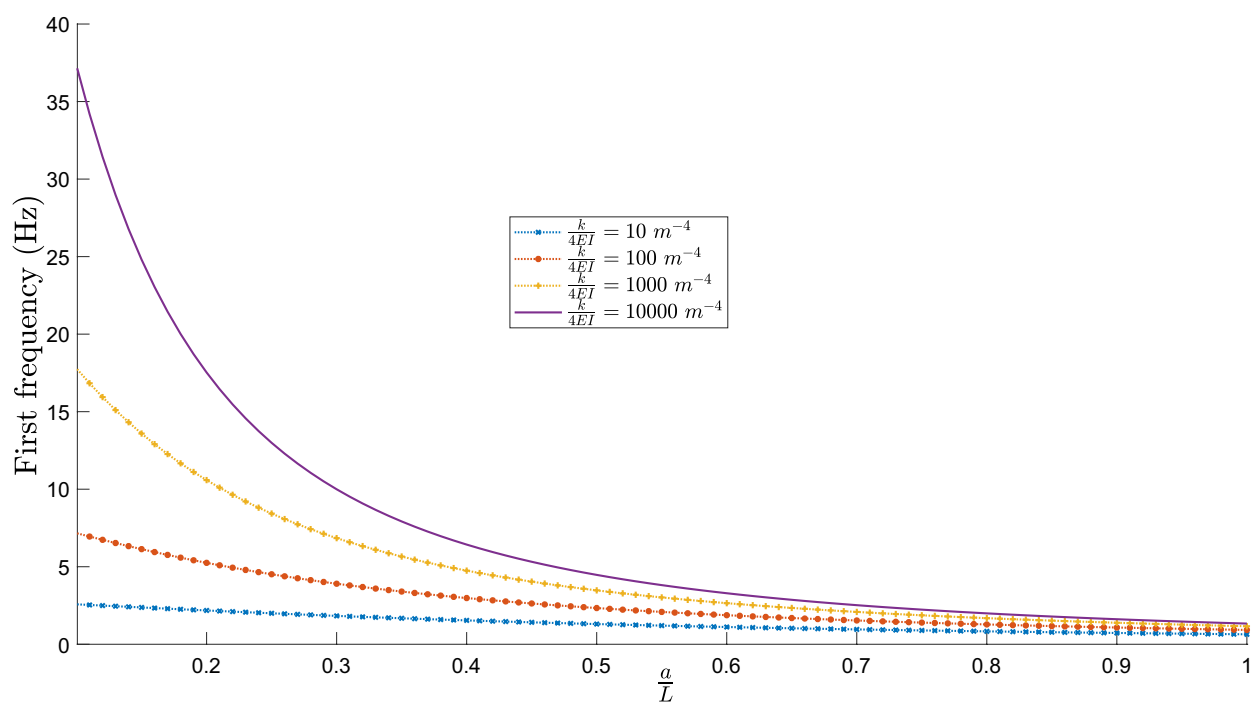

SN Applied Sciences 
Fig. 4 Influence of the coefficient $\mu$ on the first natural frequency by supposing $\frac{k}{4 E I}=1000 m^{-4}$

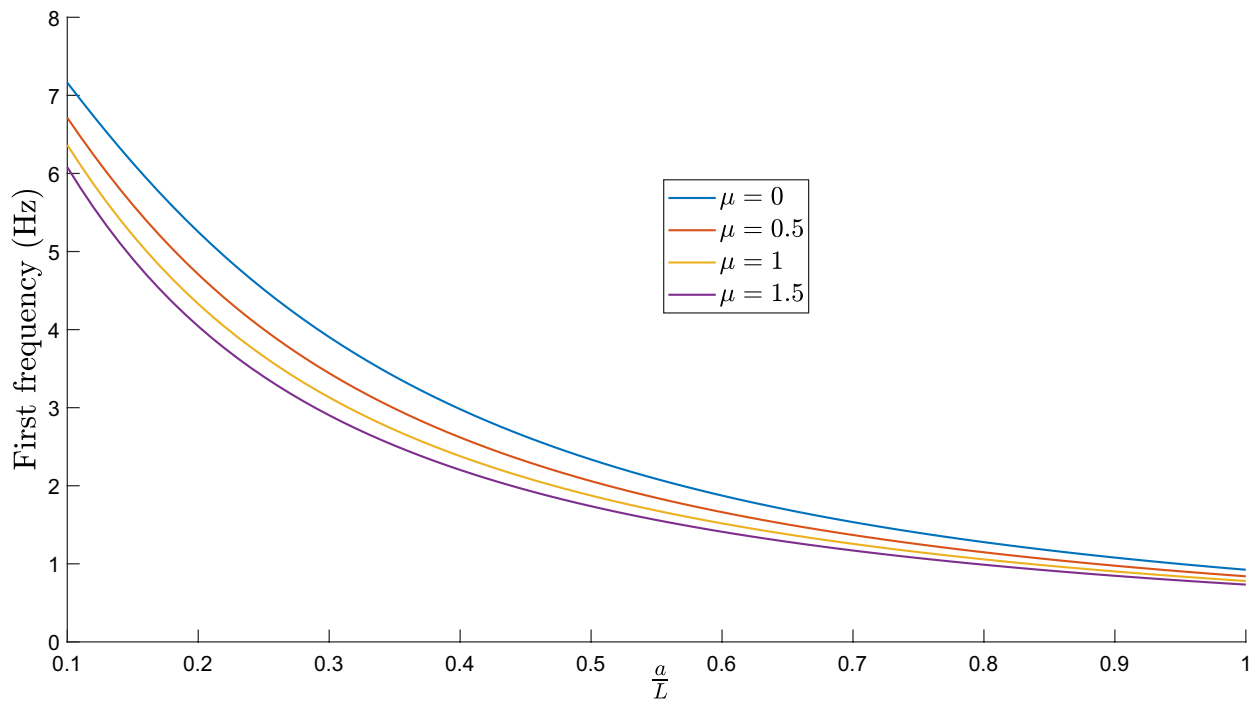

verified for rod sensors in soils like clay and sand, as shown experiments in Sect. 4 [6].

\section{Equivalent cantilevered beam}

This Section aims at comparing the variation of the first natural frequency $\omega_{1}(a)$ (previous Section) with the frequency of the equivalent free cantilevered beam of length $L_{e q}=(a+\epsilon)$ (with $\left.\epsilon<<a\right)$, which we will note $\Omega_{1}\left(L_{e q}\right)$.

\subsection{Equivalent cantilevered beam of a partially embedded Euler-Bernoulli beam in a Pasternak soil}

It has been shown experimentally [6] that when the nonburied length of the beam is varying, the first natural frequency of the partially embedded beam has a similar variation as the one of a cantilevered beam with same parameters $(E, I, \rho, A)$. This observation is also confirmed by the model that has been developed previously.

Let us define $L_{e q}(a)$ as the length of the equivalent cantilevered beam (Fig. 5) which has the same frequency as the embedded beam with the free length $a$ : in Fig. 6 , $L_{e q}(a)$ is given by the projection parallel to the length-axis of the partially embedded beam curve frequency to the cantilevered beam curve frequency. The euclidean distance (dimensionless) between a point of the curve and its projection is:

$\frac{L_{e q}(a)-a}{L}$.

As shown in Fig. 6, this distance tends to be constant, if certain hypotheses which were explained in the last

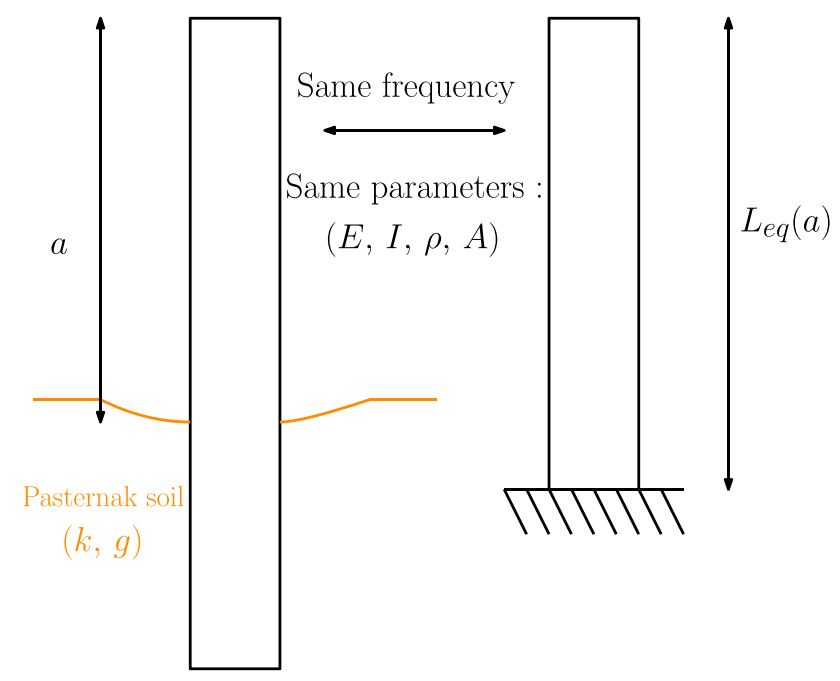

Fig. 5 Principle of the equivalent cantilevered model

Section are verified. Moreover, experimental results from literature agree with this conjecture $[5,6]$. The following investigations are aimed to capture the analytical value of this constant.

The first idea is to plot $\frac{L_{e q}(a)-a}{L}$ as a function of $\frac{a}{L}$ as shown in Fig. 7 with $\frac{k}{4 E I}=1000 \mathrm{~m}^{-4}$. In Fig. 7, it is seen that all curves become asymptotically constant. That means that there is a threshold of length which is a candidate for the assumed constant distance. This constant distance is physically a length added to the cantilevered beam, so that its first natural frequency is the same as partially embedded beam. Then, by plotting the inverse of the real part of the spatial eigenvalue $\phi_{1}$ in Fig. 7, we can approximate: 
Fig. 6 Theoritical first natural frequency as a function of $\frac{a}{L}$ for different values of $\mu \approx \frac{g L}{2 \sqrt{k E l}}$ and comparison with a cantilevered beam
Fig. 7 Asymptotic value of equivalent cantilevered beam distance
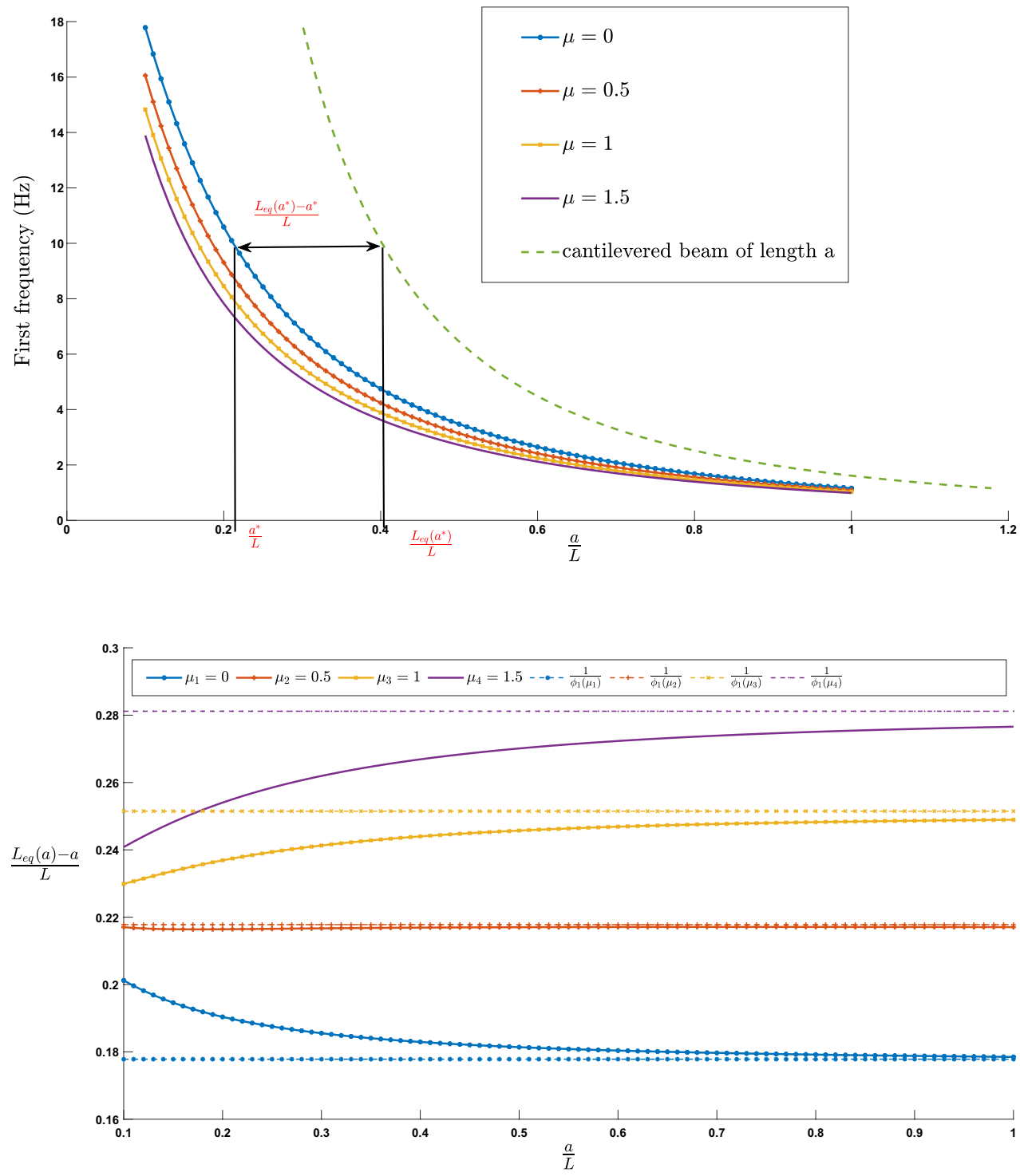

$L_{e q}(a) \approx a+\frac{L}{\phi_{1}}$.

To prepare an asymptotic development in the next section, let us suppose that the added free equivalent length is small and called $\epsilon$.

\subsection{Free cantilevered beam of equivalent length}

Let us consider the free cantilevered beam with length $L_{e q}=a+\epsilon$ (Fig. 8). Consequently, $L$ will be replaced by $L_{e q}$ in the adimensionalization. Parameters $E, l, \rho, A$ have the same definition and values as in Sect. 2 . For such a system (cantilevered at $\tilde{x}=0$ and free at $\tilde{x}=-1$ ), using Eq. (1) and
(7), boundary conditions lead us to the following characteristics equation:

$1+\cos \left(\tilde{\beta}_{r}\right) \cosh \left(\tilde{\beta}_{r}\right)=0$,

with $\tilde{\beta}_{r}$ defined in Eqs. (9) and (10).

Numerically we can write the approximation :

$$
\left\{\begin{array}{l}
\tilde{\beta}_{1}=\alpha_{1} \approx 1.8751 \\
\tilde{\beta}_{n}=\alpha_{n} \approx(2 n-1) \frac{\pi}{2}, \forall n>1 .
\end{array}\right.
$$




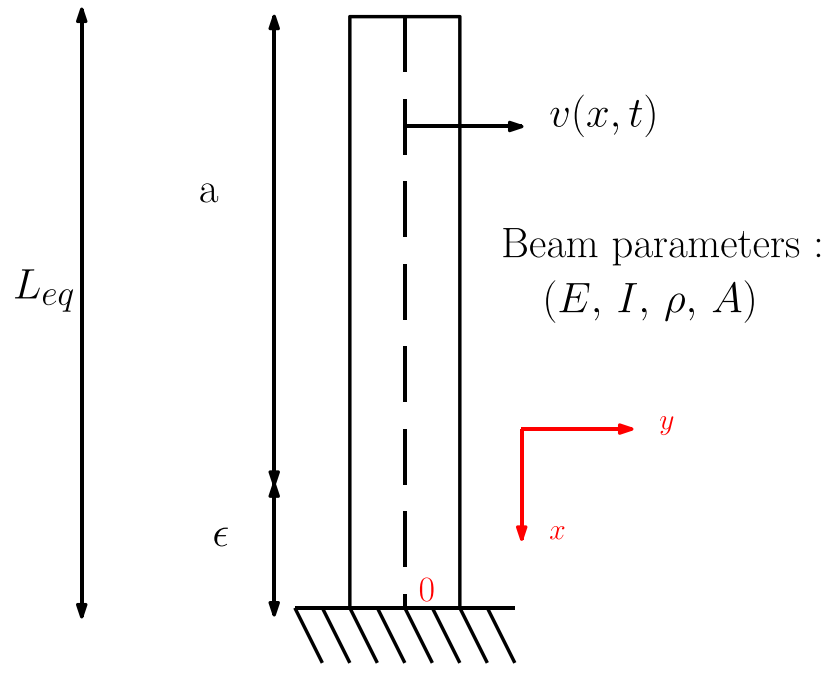

Fig. 8 Free cantilevered beam of length $L_{e q}=a+\epsilon$, with a Young Modulus $E$, an inertia $I$, a mass density $\rho$ and a cross section $A$

So, for each mode, $\tilde{\beta}_{r}$ is constant. To obtain a dimensionless coefficient, we introduce the mode-dependent coefficient as:

$c_{r}=\alpha_{r}^{2} \sqrt{\frac{E l}{\rho A}} \in \mathbb{R}, \quad \forall r \in \mathbb{N}$.

Equation (27) leads us to define $\Omega_{r}$ as a function of length:

$\Omega_{r}\left(L_{e q}\right)=\frac{C_{r}}{L_{e q}^{2}}$

$\Omega_{r}^{(i)}\left(L_{e q}\right)=(-1)^{i} \frac{(i+1) ! \Omega\left(L_{e q}\right)}{L_{e q}^{i}}, \quad \forall i \in \mathbb{N}$.

Equation (28) is useful for further investigation in this paper: When $\epsilon$ is small, a Taylor-Young development of the natural frequencies can be carried out. The results are presented in Fig. 9 for different orders of development showing that the error of the developments until the $n^{\text {th }}$ order is $\mathcal{O}\left(\epsilon^{n}\right)$ when $\epsilon \rightarrow 0$.

To compare the natural frequencies obtained by the partially embedded beam model and the equivalent cantilevered beam, their asymptotic developments will be investigated. The idea is to associate the $\epsilon$ to a SSI parameter of the partially embedded beam, and compare its derivatives from Equation (28).

\subsection{Asymptotic approach of natural frequencies of a partially embedded Euler-Bernoulli beam in a Winkler soil}

In this Section, an analytical proof for a degenerated model is investigated. We consider $\mu_{r}=0$ (Winkler soil) and $d>>L_{a}$.

We suppose now " $a$ " a constant and define the following variable:

$\epsilon=\frac{1}{\delta_{r}}$

So, the main purpose of the validation of the model of equivalent cantilevered beam is to compare (Fig. 10):

- The frequency $\Omega_{r}(\epsilon)$ of the cantilevered beam of length $a+\epsilon$ and obtained from the characteristic equation,

$$
\forall \epsilon, \quad 1+\cos \left(\frac{\rho A}{E l} \sqrt{\Omega_{r}(\epsilon)} a\right) \cosh \left(\frac{\rho A}{E l} \sqrt{\Omega_{r}(\epsilon)} a\right)=0
$$

- The pulsation $\omega_{r}(\epsilon)$ of the partially embedded beam in a Winkler soil model with the free length as " $a$ ". We neglect the effect of the depth of foundation (Eq. (22)). Here $\epsilon$ is a SSI parameter which may vary.

To reach the purpose, let us assume that the frequency is at least of class $\mathcal{C}^{1}$ in $\mathbb{R}^{+}$, and:

$\omega_{r}(\epsilon=0)=\Omega_{r}(\epsilon=0)=\Omega_{r 0}$.

The assumption in Eq. (31) has a physical sense: the smaller $\epsilon$ is, the more rigid the soil is. Consequently when $\epsilon=0$, the soil is infinitely rigid and we have a cantilevered with length $a$.

With Eq. (31) and by defining:

$\theta=\frac{a}{\Omega_{r 0}} \frac{d \omega_{r}}{d \epsilon}(\epsilon=0)$,

we have,

$$
\begin{aligned}
\omega_{r}(\epsilon) & =\Omega_{r 0}+\theta \frac{\Omega_{r 0}}{a_{\theta}} \epsilon+\mathcal{O}\left(\epsilon^{2}\right) \\
\sqrt{\omega_{r}(\epsilon)} & =\sqrt{\Omega_{r 0}}\left(1+\frac{\theta}{2 a} \epsilon\right)+\mathcal{O}\left(\epsilon^{2}\right) .
\end{aligned}
$$

Equations (22) and (24), and the boundary conditions of Sect. 2.3 give us:

$\forall \epsilon \geq 0, F(\epsilon)=0$,

where: 
Fig. 9 Numerical solution of Eq. (25) and its Taylor-Young development at order 1,2,3 and 4 (using Equation (28))

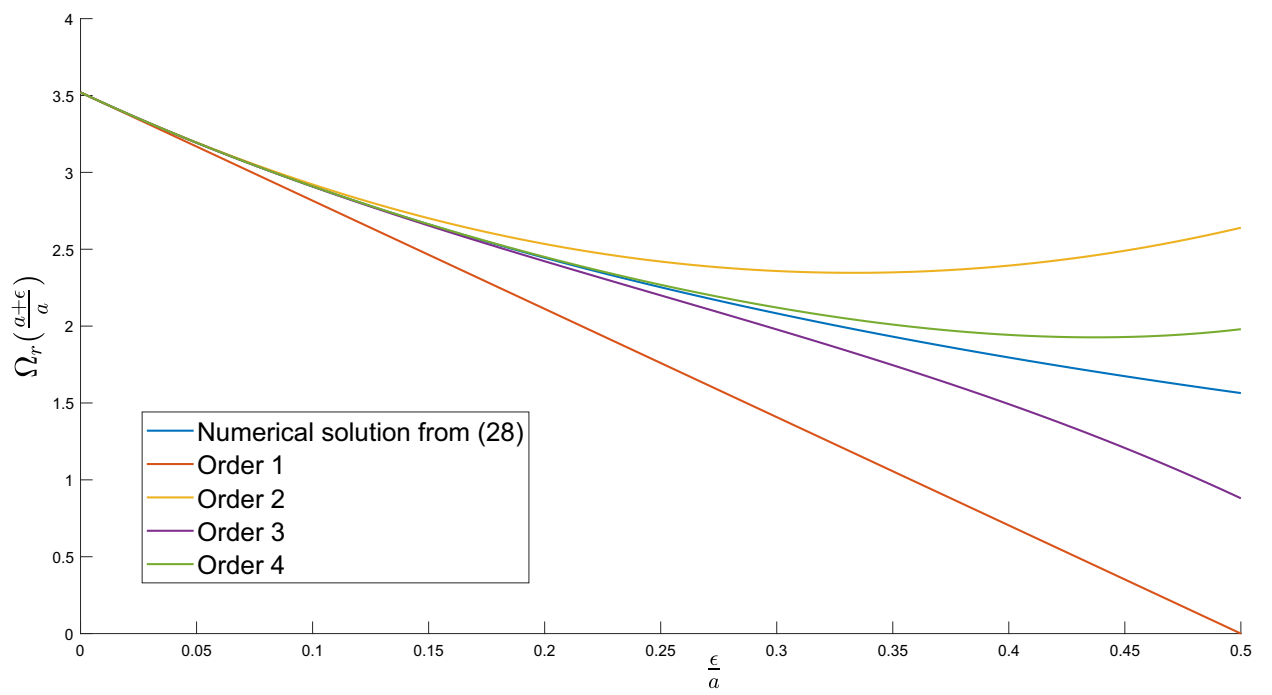

$F\left(\omega_{r}(\epsilon)\right)=\operatorname{Det}\left(C\left(\omega_{r}, 0\right)\right) \circ(\epsilon),=\operatorname{Det}\left(C\left(\omega_{r}(\epsilon), 0\right)\right.$

$$
=\left|\begin{array}{cccccc}
-\cos \left(\beta_{r}(\epsilon) a\right) & \sin \left(\beta_{r}(\epsilon) a\right) & \cosh \left(\beta_{r}(\epsilon) a\right) & -\sinh \left(\beta_{r}(\epsilon) a\right) & 0 & 0 \\
-\sin \left(\beta_{r}(\epsilon) a\right) & -\cos \left(\beta_{r}(\epsilon) a\right) & -\sinh \left(\beta_{r}(\epsilon) a\right) & \cosh \left(\beta_{r}(\epsilon) a\right) & 0 & 0 \\
1 & 0 & 1 & 0 & -1 & 0 \\
0 & \beta_{r}(\epsilon) & 0 & \beta_{r}(\epsilon) & \frac{1}{\epsilon} & -\frac{1}{\epsilon} \\
-\beta_{r}(\epsilon)^{2} & 0 & \beta_{r}(\epsilon)^{2} & 0 & 0 & 2\left(\frac{1}{\epsilon}\right)^{2} \\
0 & -\beta_{r}(\epsilon)^{3} & 0 & \beta_{r}(\epsilon)^{3} & -2\left(\frac{1}{\epsilon}\right)^{3} & -2\left(\frac{1}{\epsilon}\right)^{3}
\end{array}\right| .
$$

Equation (31) allows us to define $F$ at $\epsilon=0$, and by defining $F$ as the function null constant:

$\forall \epsilon \geq 0, \frac{d F}{d \epsilon}(\epsilon)=0=\frac{\partial \omega_{r}}{\partial \epsilon}(\epsilon) \frac{\partial F}{\partial \omega_{r}}(\epsilon)+\frac{\partial F}{\partial \epsilon}(\epsilon)$,

Equation (36) can be expanded with:

$\frac{\partial \omega_{r}}{\partial \epsilon}(\epsilon=0)=\frac{d \omega_{r}}{d \epsilon}(\epsilon=0)=\lim _{\epsilon \rightarrow 0}-\frac{\frac{\partial F}{\partial \epsilon}(\epsilon)}{\frac{\partial F}{\partial \omega_{r}}(\epsilon)}$

Equations (30) and (33) let us develop the terms in Eq. (36) as:

$-\frac{E l}{\rho A} \frac{\partial F}{\partial \epsilon}(\epsilon)=\mathcal{A}\left(\Omega_{r 0}\right) \frac{1}{\epsilon^{5}}+\mathcal{O}\left(\epsilon^{-4}\right)$,

and:

$\frac{E l}{\rho A} \frac{\partial F}{\partial \omega_{r}}(\epsilon)=\mathcal{B}\left(\Omega_{r 0}\right) \frac{1}{\epsilon^{5}}+\mathcal{O}\left(\epsilon^{-4}\right)$,

where $\mathcal{A}$ and $\mathcal{B}$ are provided in Appendix 2. Then we can find $\theta$ from Eq. (32) using Eq. (37), $\frac{\partial \omega_{r}}{\partial \epsilon}(\epsilon) \underset{\epsilon \rightarrow 0}{\sim} \frac{20 \Omega_{r 0} \theta+32 \Omega_{r 0}}{4 a}=\theta \frac{\Omega_{r 0}}{a}$,

i.e,

$\theta=-2$,

and,

$\frac{d \omega_{r}}{d \epsilon}(0)=\lim _{\epsilon \rightarrow 0}-\frac{\frac{\partial F}{\partial \epsilon}(\epsilon)}{\frac{\partial F}{\partial \omega_{r}}(\epsilon)}=-2 \frac{\Omega_{r 0}}{a}$.

This results are legitimate with the continuity hypothesis. Using Eq. (28), $\omega_{r}(\epsilon)$ has the same derivative as $\Omega_{r}$, at $\epsilon=0$. Let us write:

$\omega_{r}(\epsilon)=\Omega_{r}(\epsilon)+\underset{\epsilon \rightarrow 0}{\mathcal{O}}\left(\epsilon^{2}\right)$,

with the assumption of Eq. (13) which indicates that the flexural rigidity of the beam $E l$ is much smaller than the rigidity of the soil $k$. We assume that $\epsilon$ is near zero for the few first natural frequencies of the system. In this case, the model of equivalent cantilevered beam can be applied. In the next Section, we will validate the proposed model with experiments. 


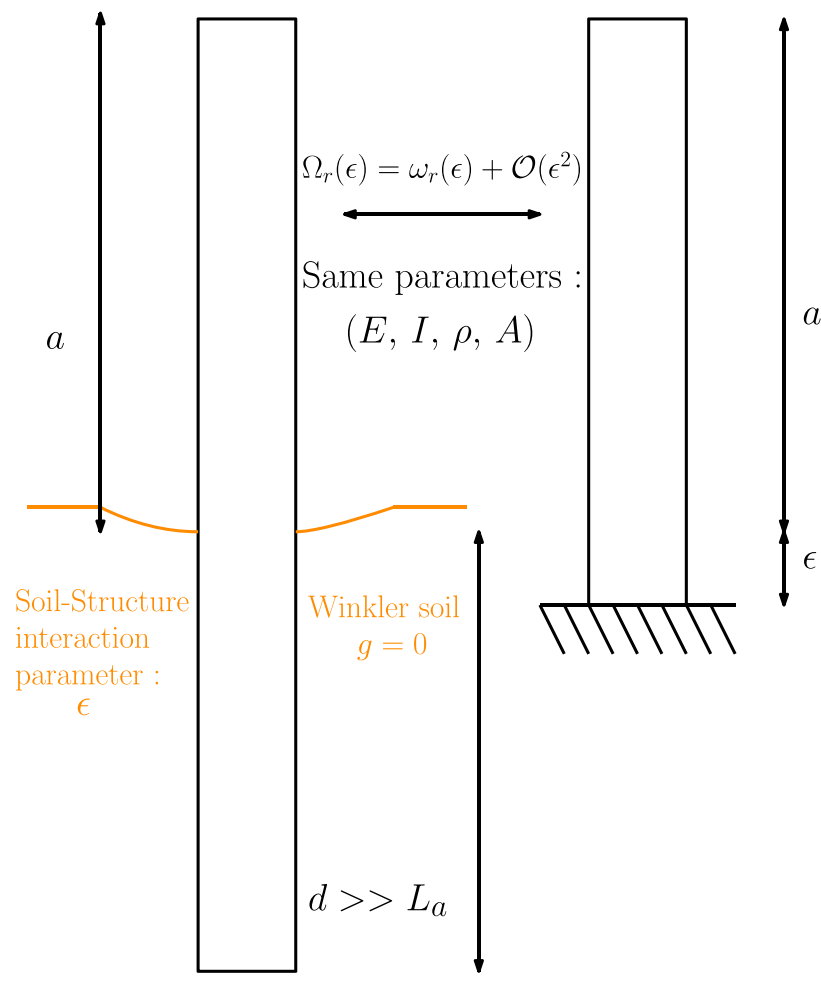

Fig. 10 Scoured beam of pulsation $\omega_{r}$ and its equivalent cantilevered beam of pulsation $\Omega_{r}$

\section{Discussion}

Let us first define an active length $L_{a}$. One of the hypothesis of equivalent cantilevered model is that the foundation depth " $d$ " is greater than $L_{a}$.

\subsection{Active length $L_{a}$}

Empirically, in literature, $L_{a}$ is defined as a length above which displacements can be neglected [19]. For example, [25] defines this length (called $L_{R}$ in this work) as:

$L_{R}=\left(\frac{4 E I}{k}\right)^{\frac{1}{4}}$.

We define this length as a function of the displacements at ground level $\left(V_{r}(0)=V_{r 0}\right.$ and $\left.V_{r}^{\prime}(0)=V_{r 0}^{\prime}\right)$ and of the pulsation $\omega_{r}$. From the previous Sections, this active length can be expressed as:

$$
\begin{aligned}
L_{a}\left(V_{r 0}, V_{r 0^{\prime}}^{\prime} \omega_{r}\right) & =\alpha\left(V_{r 0}, V_{r 0}^{\prime}\right)\left(\frac{E I}{k-\rho A \omega_{r}^{2}}\right)^{\frac{1}{4}} \\
& =\frac{\alpha\left(V_{r 0}, V_{r 0}^{\prime}\right)}{\delta_{r}},
\end{aligned}
$$

where $\alpha\left(V_{r 0}, V_{r 0}^{\prime}\right)$ is a threshold, chosen by noticing that in first Section,

$B_{3}=V_{r 0} \quad$ and $\quad B_{4}=\frac{V_{r 0}^{\prime}}{\delta_{r}}$

so,

$\left|V_{r}(x)\right| \leq \exp \left(-\delta_{r} x\right)\left(\left|V_{r 0}\right|+\left|\frac{V_{r 0}^{\prime}}{\delta_{r}}\right|\right)$

Let us provide some examples for $\alpha\left(V_{r 0}, V_{r 0}^{\prime}\right)$ :

- If we neglect values at $x=d$ under $15 \% \times\left(\left|V_{r 0}\right|+\left|\frac{V_{r 0}^{\prime}}{\delta_{r}}\right|\right)$, i.e we want $V_{r}(d) \leq 15 \% \times\left(\left|V_{r 0}\right|+\left|\frac{V_{r 0}^{\prime}}{\delta_{r}}\right|\right), \alpha\left(V_{r 0}, V_{r 0}^{\prime}\right)=2$

- If we neglect values under $5 \% \times\left(\left|V_{r 0}\right|+\left|\frac{V_{r 0}^{\prime}}{\delta_{r}}\right|\right)$,

$\alpha\left(V_{r 0}, V_{r 0}^{\prime}\right)=3$,
- If we neglect values under $1 \% \times\left(\left|V_{r 0}\right|+\left|\frac{V_{r 0}^{\prime}}{\delta_{r}}\right|\right)$, $\alpha\left(V_{r 0}, V_{r 0}^{\prime}\right)=5$,

In other terms, $\alpha\left(V_{r 0}, V_{r 0}^{\prime}\right)$ is an integer defining the active length $L_{a}$ proportional to the equivalent added length $\left(\epsilon=\frac{1}{\delta_{r}}\right.$ ) described previously.

\subsection{Validation with experimental results}

This part aims to validate the model of equivalent cantilevered beam with experimental results obtained for an aluminum rod in sand [6]. Table 1 summarizes the numerical values of system parameters.

The experimental approach consists in repeating the following protocol for different values of the free length " $a$ ":

- Give a impulse using a hammer and acquire the response of the beam via a sensor,

- For each signal, use a fast Fourier transformation to analyse the frequency response in order to obtain natural frequencies by "peak-peacking".

- Repeat again five times and take the mean of natural frequencies.

The sensor used is an accelerometer GCDC X-series [9]. The mass $m_{s}$ of the sensor reads,

$m_{s}=40.8 g$ 
We should change the boundary condition defined in Eq. (11). Equations (12), (22) and (23) do not change, and we add a point mass at the top of the rod:

$\tilde{V}_{r}^{\prime \prime}\left(\frac{-a}{L}\right)=0$,

$\tilde{V}_{r}^{(3)}\left(\frac{-a}{L}\right)=-m \omega_{r}^{2} \tilde{V}_{r}\left(\frac{-a}{L}\right)$.

Figure 11 plots the first natural frequency as a function of $\frac{a}{L}$ using the model derived in the previous Sections, with the new boundary conditions of Eq. ((49)).

We consider $g=0$, consequently the soil is a perfect Winkler soil [33], with the parameter $k$ derived from Ménard formula [18] and experimentally determined soil rheological parameter $\alpha=\frac{1}{3}$. As for the scoured beam, we add a point mass $m_{s}$ to the equivalent cantilevered beam described in Sect. 3.2 and we can write the analytical formula of the first frequency [30]:

$\Omega_{1}\left(L_{e q}\right)=\sqrt{\frac{3 E I}{L_{e q}^{3}\left(0.24 \times \rho A L_{e q}+m_{s}\right)}}$.

Given the data in Table 1, we assume that the added length $\epsilon$ is independent of the pulsation $\omega_{r}$ :

Table 1 Characteristics of the soil and the beam with " $k$ " calculated from [18] with $\alpha=\frac{1}{3}$

Fig. 11 Variation of the first frequency with the free length " $a$ ": Experimental results vs analytical results from Sect. (2) with boundary condition of ((49)) $\epsilon_{\text {model }} \approx\left(\frac{4 E I}{k}\right)^{\frac{1}{4}}$.

In Table 2 the detected first frequency $\epsilon_{\text {model }}$ is compared to the experimental first frequency $\epsilon_{\text {exp }}$.

We can see an error of $5 \%$ probably due to the approximation of non-dependent modes, and on the other hand to the hypothesis that there is no shear between the soil springs $(g=0)$. Vlasov [31] showed that when the soil is not infinite, a relation between $k$ and $g$ exists and this is of course the case here (experiments made in laboratory with a finite volume of soil). In fact, if we consider shear between springs, $\epsilon_{\text {model }}$ may change.

\section{Conclusion and perspectives}

On one hand, this study proposes a model that allows the indirect monitoring using rod sensors, where external forces as wind or water flow are candidates for continuous exterior lateral excitation.

The proposed monitoring parameter (equivalent length) allows to link directly the first frequency (low frequencies) to the scour depth: This is practical method to solve quickly (from the point of view of calculation cost) the inverse problem induced by scour.

Moreover, piers are modeled as beams with the assumption that the flexural rigidity of the beam (4EI) is much less than the rigidity of soil $(k)$. In the perfect hypothesis case (i.e deep foundation), this kind of structures implies a small equivalent length error for a Winkler
Table 2 Comparison of the free equivalent length $\epsilon$ between experimental data and from the model

\begin{tabular}{ll}
\hline$\epsilon_{\text {model }}$ & $8.24 \mathrm{~cm}$ \\
\hline$\epsilon_{\text {exp }}$ & $8.67 \mathrm{~cm}$ \\
\hline
\end{tabular}

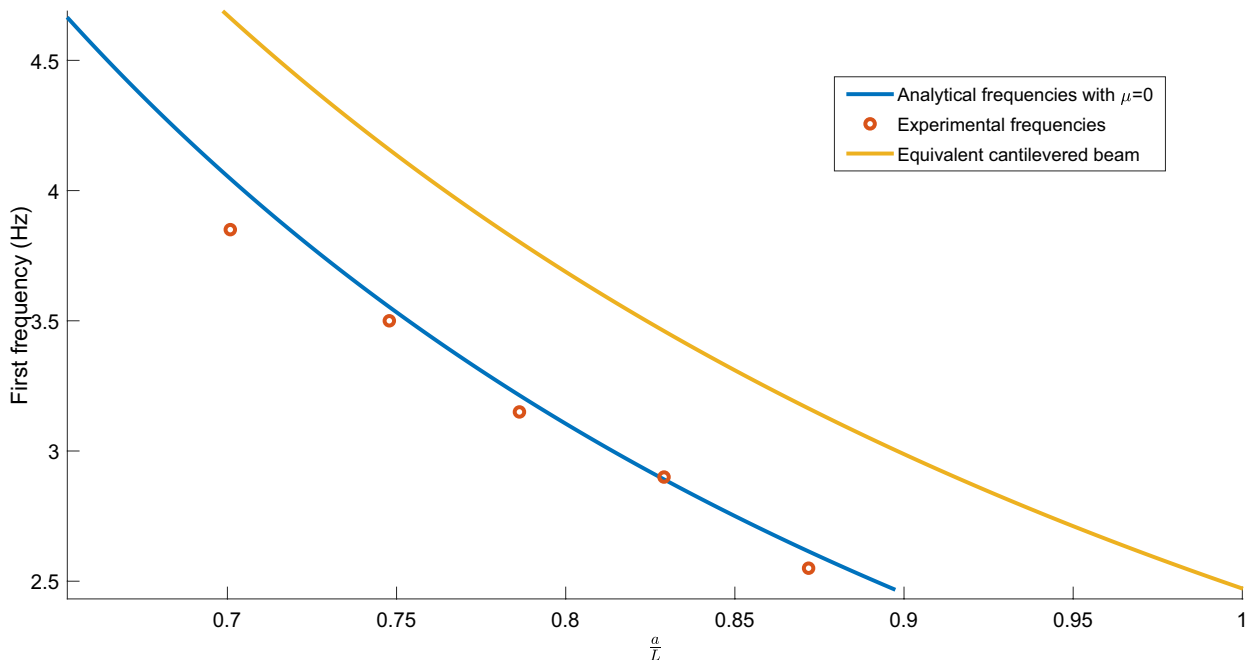


soil: an analytical proof was carried out. Numerical results implemented in Matlab ${ }^{\circledR}$ imply that for Pasternak soil, the conclusion should be the same (Fig. 7). Finally, the real part of the eigenvalues $\lambda_{r}$ [Eq. (14)] are intrinsically linked to the added equivalent cantilevered length. With the experimental results, the equivalent cantilevered beam concept has been consolidated with a new analytical model of Soil Structure Interaction (SSI) mixing Euler-Bernoulli and Pasternak models. Also, the model can be extended to several layers of soil of soil by assuming continuity of cinematic variables: the dimension of the matrix " $C$ " in Appendix 1 will increase. In addition, considering an added point mass, results do not change the interpretation and encourages us to extend the model for bridge pier considering the bridge deck as an added mass.

On the other hand, the model is supposed to be applicable for the direct scour monitoring using the bridge pier vibration. However, future studies should focuses on the quantification of the error and the limit case. For instance, when $d=L_{a}$, new type of boundary conditions appear. For example the null displacement at the end of the beam can be replaced by a rocking rotation as shown [13]. Also, our study neglects the coupling with bridge deck which is considered as an added mass: the vibration mode of the pier are independent of the bridge deck vibrations [7]. Then, the hypothesis of rigidity of the beam much lower than the stiffness of the soil and the active length depends on the soil parameters and the pier configuration. This study is intended to be analytic and is a new approach of scour monitoring problems. Experiments are here to fortify the model and open some discussions. The hypothesis of the model are large in order to write a global mathematical model. However, each soil and structure interaction model has its limits with a specific quantification of the hypothesis. For that reason, the equivalent cantilevered beam model is not always verified for bridge piers.

\section{Compliance with ethical standards}

Funding All co-authors have seen and agree with the contents of the manuscript and there is no financial interest to report. We certify that the submission is original work and is not under review at any other publication. Some or all data, models, or code that support the findings of this study are available from the corresponding author upon reasonable request. All data, models, and code generated or used during the study appear in the submitted article.

Open Access This article is licensed under a Creative Commons Attribution 4.0 International License, which permits use, sharing, adaptation, distribution and reproduction in any medium or format, as long as you give appropriate credit to the original author(s) and the source, provide a link to the Creative Commons licence, and indicate if changes were made. The images or other third party material in this article are included in the article's Creative Commons licence, unless indicated otherwise in a credit line to the material. If material is not included in the article's Creative Commons licence and your intended use is not permitted by statutory regulation or exceeds the permitted use, you will need to obtain permission directly from the copyright holder. To view a copy of this licence, visit http://creativecommons .org/licenses/by/4.0/.

\section{Appendix 1: Expression of C (Eq. (24))}

$$
\text { Case I: } \tilde{\mu}_{r}<1
$$

$$
\left.\begin{array}{cc}
0 & 0 \\
0 & 0 \\
-1 & 0 \\
\phi_{1} & -\phi_{2} \\
-\left(\phi_{1}^{2}-\phi_{2}^{2}\right) & 2 \phi_{1} \phi_{2} \\
\left(\phi_{1}^{3}-3 \phi_{1} \phi_{2}^{2}\right)\left(\phi_{2}^{3}-3 \phi_{1}^{2} \phi_{2}\right)
\end{array}\right]
$$

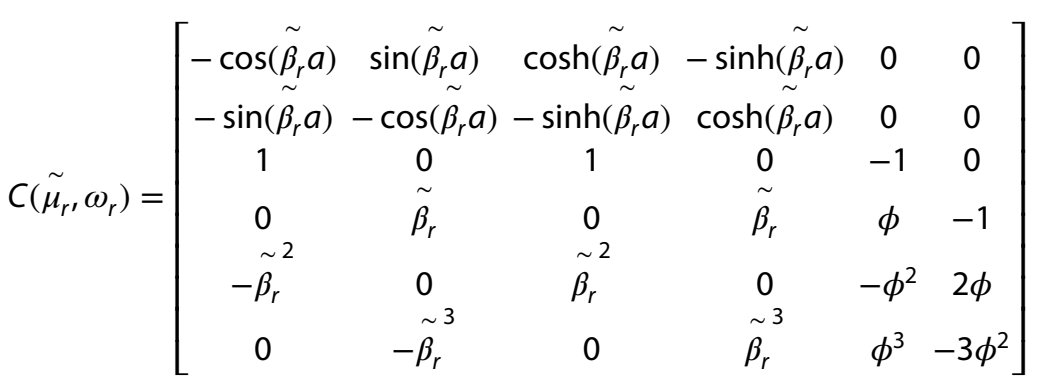


Case III: $\tilde{\mu}_{r}>1$

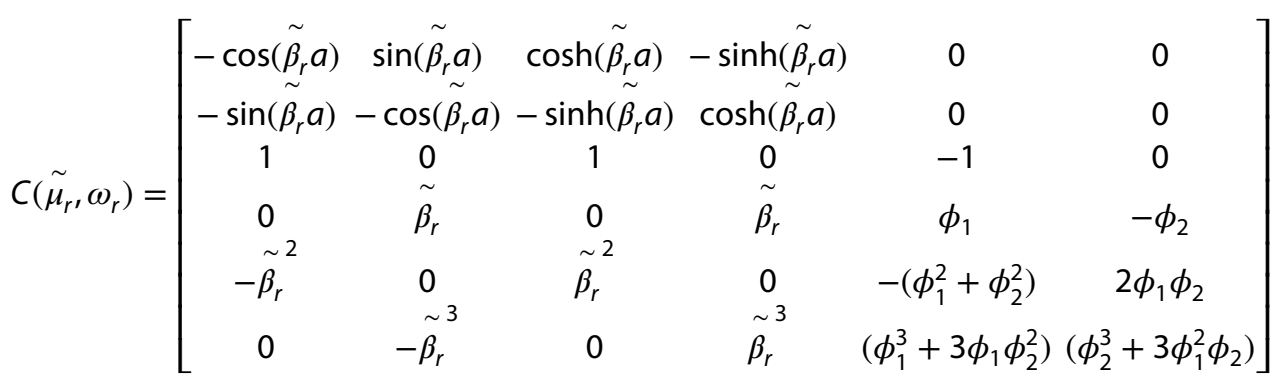

\section{Appendix 2: Expression of $\mathcal{A}$ and $\mathcal{B}$ (Eqs. (38) and (39))}

$$
\begin{aligned}
\mathcal{A}\left(\Omega_{r 0}\right)= & \left(20 \Omega_{r 0} \theta+32 \Omega_{r 0}\right)\left(\cos \left(\frac{\rho A}{E l} \Omega_{r 0} a\right) \sinh \left(\frac{\rho A}{E l} \Omega_{r 0} a\right)\right. \\
& \left.-\cosh \left(\frac{\rho A}{E l} \Omega_{r 0} a\right) \sin \left(\frac{\rho A}{E l} \Omega_{r 0} a\right)\right) \\
\mathcal{B}\left(\Omega_{r 0}\right)= & 4 a\left(\cos \left(\frac{\rho A}{E l} \Omega_{r 0} a\right) \sinh \left(\frac{\rho A}{E l} \Omega_{r 0} a\right)\right. \\
& \left.-\cosh \left(\frac{\rho A}{E l} \Omega_{r 0} a\right) \sin \left(\frac{\rho A}{E l} \Omega_{r 0} a\right)\right)
\end{aligned}
$$

\section{References}

1. Basmaji B (2017) Développement d'un modèle analytique d'interaction sol-structure pour l'étude du comportement mécanique des structures soumises à un mouvement de terrain : influence des déformations de cisaillement et de la plasticité. PhD thesis, Université de Lorraine

2. Briaud J-L, Ting C. K Francis, Chen H. C, Rao G, Suresh P, Gengsheng W (1999) SRICOS: Prediction of scour rate in cohesive soils at bridge piers. J Geotech Geoenviron Eng 125(4):237-246

3. Bodeux JB, Golinval J C (2001) Application of ARMAV models to the identification and damage detection of mechanical and civil engineering structures. Smart Mater Struct 10(3):479-489

4. Bao T, Liu ZL, Bird K (2019) Influence of soil characteristics on natural frequency-based bridge scour detection. J Sound Vib 446:195-210

5. Boujia N, Schmidt F, Chevalier C, van Bang DP (2019) Effect of Scour on the Natural Frequency Responses of Bridge Piers: Development of a Scour Depth Sensor. Infrastructures 4(2):21

6. Boujia N, Schmidt F, Chevalier C, Siegert D, Pham Van Bang DP (2020) Distributed optical Fiber-based approach for Soil-Structure Interaction. Sensors 20(1):1

7. Bao Ting, Swartz R. Andrew, Vitton Stanley, Sun Ye, Zhang Chao, Liu Zhen (2017) Critical insights for advanced bridge scour detection using the natural frequency. J Sound Vib 386:116-133

8. Cawley P, Adams RD (1979) The location of defects in structures from measurements of natural frequencies. J Strain Anal Eng Des 14(2):49-57

9. Gulf Coast Data Concepts. USB-Accelerometer 3-axis Self Recording Accelerometer X16-1D (2020)

10. Forde MC, McCann DM, Clark MR, Broughton KJ, Fenning PJ, Brown A (1999) Radar measurement of bridge scour. NDT E Int 32(8):481-492
11. Foti S, Sabia D (2011) Influence of foundation scour on the dynamic response of an existing bridge. J Bridge Eng 16(2):295-304

12. Farrar Charles R, Worden Keith (2007) An introduction to structural health monitoring. Philos Trans R Soc A: Math Phys Eng Sci 365(1851):303-315

13. Gazetas G (1983) Analysis of machine foundation vibrations: State of the art. 2(1):2-42

14. Heidarpour $\mathrm{M}$, Afzalimehr $\mathrm{H}$, Izadinia $\mathrm{E}$ (2010) Reduction of local scour around bridge pier groups using collars. Int J Sedim Res 25(4):411-422

15. Iwinski T (1967) Chapter 2: Theory of beams, second. Pergamon, Bergama, pp 14-70

16. Kato Masafumi, Shimada Shizuo (1986) Vibration of PC bridge during failure process. J Struct Eng 112(7):1692-1703

17. Lagasse PF, Schall JD, Johnson F, Richardson EV, Chang F (1995) Stream stability at highway structures

18. Menard L, Bourdon G, Gambin M (1969) Méthode générale de calcul d'un rideau ou d'un pieu sollicité horizontalement en fonction des resultats pressiomètriques sol. Sol Soils Vl:16-29

19. Makris N, Gazetas G (1993) Displacement phase differences in a harmonically oscillating pile. Géotechnique 43(1):135-150

20. Maia NMM, Silva JMM (2001) Modal analysis identification techniques. Philos Trans: Math Phys Eng Sci 359(1778):29-40

21. Melville BW, Yee-Meng C (1999) Time scale for local scour at bridge piers. J Hydraul Eng 126(10):1

22. Pasternak PL (1954) On a new method of analysis of an elastic foundation by means of two constants. osudarstvennoe Izdatelstvo Literaturi po Stroitelstvu I Arkhitekture, Moscow (URSS)

23. Prendergast LJ, Gavin K (2014) A review of bridge scour monitoring techniques. J Rock Mech Geotech Eng 6(2):138-149

24. Prendergast LJ, Hester D, Gavin K, O'Sullivan JJ (2013) An investigation of the changes in the natural frequency of a pile affected by scour. J Sound Vib 332(25):6685-6702

25. Randolph MF (1981) The response of flexible piles to lateral loading. Géotechnique 31(2):247-259

26. Salawu OS (1997) Detection of structural damage through changes in frequency: a review. Eng Struct 19(9):718-723

27. Seo Junwon, Hu Jong Wan, Lee Jaeha (2016) Summary review of structural health monitoring applications for highway bridges. J Perform Construct Facilit 30(4):04015072

28. Tanahashi H (2004) Formulas for an infinitely long BernoulliEuler beam on the Pasternak model. Soils Fond 44:1

29. Lunne T, Robertson PK, Powell JJM (2009) Cone-penetration testing in geotechnical practice. Soil Mech Found Eng 46(6):237-237

30. Turhan $O(2000)$ On the fundamental frequency of beams carrying a point mass: Rayleigh approximations versus exact solutions. J Sound Vib 230(2):449-459

31. Vlasov VZ, Leontiev UN (1966) Beams, plates, and shells on elastic foundation 
32. Wardhana K, Fabian $\mathrm{CH}$ (2003) Analysis of recent bridge failures in the United States. J Perform Construct Facilities 17(3):1

33. Winker E (1867) Die Lehre von der Elastizität und Festigkeit (on elasticity and fixity) dominicus

34. Yeung RW (1981) Added mass and damping of a vertical cylinder in finite-depth waters. Appl Ocean Res 3(3):119-133

35. Yankielun NE, Zabilansky L (1999) Laboratory investigation of time-domain reflectometry system for monitoring bridge scour. J Hydraul Eng 125(12):1279-1284
36. Zhao M, Cheng L (2010) Numerical investigation of local scour below a vibrating pipeline under steady currents. Coast Eng 57(4):397-406

37. Zarafshan A, Iranmanesh A, Ansari F (2012) Vibration-based method and sensor for monitoring of bridge scour. J Bridge Eng 17(6):829-838

Publisher's Note Springer Nature remains neutral with regard to jurisdictional claims in published maps and institutional affiliations. 